\title{
A Web-based module and online video for pain management education for caregivers of children with fractures: A randomized controlled trial
}

\author{
Stevi Golden-Plotnik, MD*; Samina Ali, MDCM ${ }^{\ddagger}$; Amy L. Drendel, DO, MS ${ }^{\S}$; Tammy Wong, BSc*; \\ Frank Ferlisi, MD*; Sydney Todorovich, BMSc, MPH ${ }^{\top}$; Kyle Canton, HBSc*; Michael Miller, PhD*; \\ Julia Younan, BMSc"; Sharlene Elsie, BSc"; Naveen Poonai, MD, MSc*ף॥
}

\section{ABSTRACT}

Introduction: Over $80 \%$ of children experience compromise in functioning following a fracture. Digital media may improve caregiver knowledge of managing fracture pain at home.

Objectives: To determine whether an educational video was superior to an interactive web-based module (WBM) and verbal instructions, the standard of care (SOC).

Methods: This randomized trial included caregivers of children 0-17 years presenting to the emergency department (ED) with non-operative fractures. Primary outcome was the gain score (pre-post intervention) on a 21-item questionnaire testing knowledge surrounding pain recognition and management for children with fractures. Secondary outcomes included survey of caregiver confidence in managing pain (five-item Likert scale), number of days with difficulty sleeping, before return to a normal diet, and work/school missed.

Results: We analyzed 311 participants (WBM 99; video 108; SOC 104) with a mean (SD) child age of 9.6 (4.2) years, of which $125 / 311(40.2 \%)$ were female. The video (delta $=2.3,95 \% \mathrm{Cl}: 1.3,3.3 ; \mathrm{p}<0.001$ ) and WBM (delta=1.6; $95 \% \mathrm{Cl}: 0.5,2.6 ; \mathrm{p}=0.002)$ groups had significantly greater gain scores than the SOC group. The mean video gain score was not significantly greater than WBM (delta $=0.7 ; 95 \% \mathrm{Cl}$ : $-0.3,1.8 ; p=0.25)$. There were no significant differences in caregiver confidence $(p=0.4)$, number of absent school days $(p=0.43)$, nights with difficulty sleeping $(p=0.94)$, days before return to a normal diet $(p=0.07)$, or workdays missed $(p=0.95)$.

Conclusions: A web-based module and online video are superior to verbal instructions for improving caregiver knowledge on management of children's fracture pain without improvement in functional outcomes
RÉSUMÉ

Introduction: Plus de $80 \%$ des enfants ayant subi une fracture éprouvent un certain degré de dysfonctionnement. Ainsi, la transmission d'information à l'aide de médias numériques pourrait améliorer les connaissances des aidants en ce qui concerne le soulagement de la douleur à domicile.

Objectif: L'étude visait à déterminer si une vidéo éducative donnerait de meilleurs résultats qu'un module interactif sur le Web ou des instructions verbales, norme actuelle en matière de soins.

Méthode: Il s'agit d'un essai avec répartition aléatoire auquel ont participé des aidants d'enfants âgés de 0 à 17 ans, qui ont été traités au service des urgences pour des fractures n'ayant pas nécessité d'opération. Le principal critère d'évaluation consistait en le nombre de points gagnés (avant et après intervention) à un questionnaire en 21 points sur les connaissances des aidants quant à la reconnaissance et à la prise en charge de la douleur chez des enfants ayant subi une fracture. Les critères d'évaluation secondaires comprenaient l'appréciation du degré de confiance des aidants en matière de soulagement de la douleur (échelle de Likert en 5 points) ainsi que le nombre de jours avec troubles du sommeil; avant le retour à une alimentation normale et d'absence au travail ou à l'école.

Résultats: Ont été analysés les résultats de 311 participants (module : 99; vidéo : 108; soins usuels : 104); l'âge moyen (écart-type) des enfants était de 9,6 ans $(4,2)$ et 125 jeunes sur $311(40,2 \%)$ étaient des filles. Le nombre de points gagnés dans les groupes informés par vidéo (delta $=2,3$; IC à $95 \%: 1,3$ - 3,3; $p<0,001$ ) ou par le module (delta =1,6; IC à $95 \%: 0,5-2,6$; $p=0,002$ ) était nettement supérieur à celui enregistré dans le groupe des soins usuels. Par contre, le gain moyen de points dans le groupe informé par vidéo différait peu de celui obtenu

From the *Department of Paediatrics, Western University, London, ON; †Schulich School of Medicine and Dentistry, University of Western Ontario, London, ON; ‡Department of Pediatrics, University of Alberta, Women and Children's Health Research Institute, Edmonton, AB; $\S$ Department of Pediatrics, Medical College of Wisconsin, Milwaukee, WI; IDivision of Paediatric Emergency Medicine, Western University, London, ON; and the ॥Children's Health Research Institute, London Health Sciences Centre, London, ON.

Correspondence to: Dr. Naveen Poonai, Paediatric Emergency Department, Children's Hospital, London Health Sciences Centre, 800 Commissioners Road East, London, ON N6A 2V5; Email: naveen.poonai@Ihsc.on.ca 
dans le groupe informé par le module (delta $=0,7$; IC à $95 \%$ : $-0,3-1,8 ; p=0,25)$. Enfin, il n'y avait pas d'écart important quant au degré de confiance des aidants $(p=0,4)$ ni au nombre de jours d'absence à l'école $(p=0,43)$; avec troubles du sommeil $(p=0,94)$; avant le retour à une alimentation normale $(p=0,07)$ et d'absence au travail $(p=0,95)$.

Conclusions: Le module sur le Web ou la vidéo en ligne se sont révélés plus efficaces que la simple transmission d'instructions verbales en ce qui concerne l'amélioration des connaissances des aidants sur la prise en charge de la douleur chez les enfants ayant subi une fracture, sans toutefois se traduire par une amélioration des résultats fonctionnels.

Keywords: fracture, pain, digital education, paediatrics

\section{INTRODUCTION}

Orthopedic injuries are common painful conditions, ${ }^{1}$ comprising more than $10 \%$ of emergency department (ED) visits in children. ${ }^{2}$ Fractures comprise approximately $10 \%$ to $25 \%$ of injuries in children. ${ }^{3}$ The most severe pain following an orthopedic injury occurs within the first 48 hours following discharge, and over $80 \%$ of children experience compromise in at least one functional domain. ${ }^{4}$ Limited comprehension of discharge instructions can be attributed to disparity between literacy levels and written discharge material. ${ }^{5}$ In children with musculoskeletal injuries, little information is provided to caregivers on managing pain following discharge. ${ }^{6}$ As a possible consequence, it has been reported that only $72 \%$ of parents provide pain relief after an injury, and only $28 \%$ use pharmacologic therapies. ${ }^{6}$ In addition, almost a third of parents are reportedly dissatisfied with the pain relief that their child receives at home following ED care for a fracture. ${ }^{7}$ There are challenges regarding the best way to disseminate information on the recognition and home management of pain in children. Indeed, ED clinicians are often constrained by the time that they can devote to comprehensive caregiver education. As a result, the content of discharge instructions is often highly variable $^{8,}, 9$ and is poorly understood by most ED patients. ${ }^{10,11}$ Digital media approaches overcome literacy barriers and have shown benefit in caregiver knowledge acquisition in autism, ${ }^{12}$ type I diabetes, ${ }^{13}$ epilepsy, ${ }^{14}$ asthma, ${ }^{15}$ and juvenile idiopathic arthritis. ${ }^{16}$ In pediatric fractures, however, such interventions have not been explored. Almost $75 \%$ of North American households have Internet access, ${ }^{17}$ and up to $90 \%$ of parents access the Internet for health resources. ${ }^{18,19}$ Therefore, digital media may be a feasible and efficient way to disseminate information to caregivers in a busy ED. Given the frequency of pediatric fractures and the well-documented suboptimal management of children's pain following ED discharge, we sought to assess caregiver knowledge acquisition and child functional outcomes for two novel digital media strategies (an interactive Web-based module [WBM] and a video) for children who sustained a nonoperative fracture. Demonstrating the effectiveness of these strategies in terms of knowledge improvement is an important initial step to inform their further development and utilization.

\section{METHODS}

\section{Study design and setting}

We conducted an open-label, parallel group, randomized, three-arm superiority trial to test the hypothesis that a novel educational video was superior to 1 ) a novel interactive WBM and 2) verbal instructions, the standard of care (SOC), with respect to caregiver knowledge acquisition in the ED on the recognition and management of fracture pain in children. We recruited participants from the pediatric ED of the Children's Hospital, London Health Sciences Centre in London, Ontario from September 2015 to November 2016. Our institution is a tertiary care pediatric centre with an average annual census of 37,000 visits, including over 1,000 nonoperative fractures. The study received approval from Western University's Health Sciences Research Ethics Board (www.clinicaltrials.gov NCT02435498).

\section{Participants}

We included the primary caregivers of all children ages 0 to 17 years who were diagnosed with a nonoperative fracture and were managed by the attending emergency physician. We excluded caregivers with a language barrier precluding comprehension of study-related tasks or lack of a home computer with Internet access; children with fractures requiring operative reduction, external fixation, or associated with multisystem trauma; 
children transferred from another facility; and children with a history of renal, liver disease, bleeding diathesis, chronic pain, or pregnancy.

A research assistant (RA) unaware of the study hypothesis assessed eligibility, obtained informed consent, and performed all correspondence with participants. Participants were recruited consecutively for 7 days a week between 1700 and 2200 hours, following the initial physician assessment.

\section{Interventions}

Participants were randomized using a 1:1:1 allocation, with a block size of four or six to receive pain management education with a WBM, video, or SOC based on a computer-based randomization sequence found at http:// www.randomization.com. All interventions were administered in the ED, and participants in the WBM and video group were provided online access to their respective interventions for 120 hours following discharge. Allocation concealment was performed using sequentially numbered, opaque, sealed envelopes. We collected demographic information from all caregivers, including age, highest education level, employment status, relationship to the child, and history of fractures in their children.

Participants were administered in the ED, a novel 21-item knowledge questionnaire (Supplementary Appendix 1) on the recognition and management of postfracture pain using SurveyMonkey. This was immediately followed by the intervention with the exception of the SOC, whose timing was variable, depending on the availability of the bedside nurse. An identical knowledge questionnaire was administered immediately following the intervention, in an effort to avoid cross-contamination between study groups, with participants potentially accessing additional sources of education.

At 120 hours post-discharge, participants were emailed a link to a five-item survey (Table 1) hosted on SurveyMonkey that assessed caregiver confidence in managing pain at home using a five-item Likert scale and functional outcomes. The question stems for the functional outcomes were modified from similar outcomes assessed by Drendel et al. in their study of children with upper extremity fractures. ${ }^{20}$

\section{Tool development}

The knowledge questionnaire was developed de novo using a focus group of four investigators (SGP, NP, SA, AD) and two ED nurses. It was pilot tested among another five pediatric ED physicians and five ED nurses. As a final step, the tool was pre-tested among 10 lay caregivers for content validity, face validity, comprehension, and readability. It was scored from zero to 21 , with one point for each correct answer and no penalty for guessing.

The WBM was developed de novo using WordPress, which covered recognition of pain, over-the-counter analgesic dosing and indications; risks and safety in children; signs and symptoms of pain in children; and misconceptions about treating pain. Images used in the WBM were taken from two online sources of stock images. ${ }^{21,22}$ Participants used their touchpad to click on the screen to activate the intervention's interactive component that consisted of a dose calculator for analgesics.

The video was a 5 -minute instructional clip, entitled Treating Pain at Home and hosted on the WordPress platform. It was developed de novo by pediatric investigators at the Medical College of Wisconsin for a previous study ${ }^{23}$ using a focus group of pediatric providers. It was informed by qualitative interviews of caregivers that identified frequently asked questions about outpatient pediatric pain and its management. The video was recorded using a Betacam video recorder, and its utility was evaluated in a pediatric ED population. ${ }^{23}$ Both the WBM and video contained identical factual content that was presented differently. Both the WBM and video can be accessed at www.fracturepain.com (password: londonpain).

The SOC included verbal instructions provided by the bedside nurse on dosing and frequency of over-thecounter analgesics and when to return to the ED. Although the content of the SOC was outlined by the nursing directive at our centre, it was not standardized in order to optimally reflect the SOC in most EDs, including our own. ${ }^{24}$ The bedside nurse and physician were asked not to provide discharge teaching to participants in the WBM and video groups, and therefore they did not receive the SOC. All participants received a paper-based handout outlining how to care for the cast or splint and when to return to the ED (Supplementary Appendix 2). Questions about care following discharge were answered by the treating physician. At discharge, participants in the WBM and video groups were provided with a unique username and password to access their respective interventions following discharge. If participants did not access the intervention within 24 hours, they received a phone call from the RA confirming that they could access the site. The number of times that the WBM or video was accessed and the 
Digital media educational interventions for fracture pain

\begin{tabular}{|c|c|c|c|c|}
\hline Survey item & $\begin{array}{l}\text { Standard of care } \\
\text { Number }(\%)\end{array}$ & $\begin{array}{l}\text { Web-based module } \\
\text { Number }(\%)\end{array}$ & $\begin{array}{l}\text { Educational video } \\
\text { Number (\%) }\end{array}$ & $p$-value \\
\hline $\begin{array}{l}\text { How confident did you feel managing your child's pain at home, after } \\
\text { being sent home from the emergency department? }\end{array}$ & $(n=84)$ & $(n=74)$ & $(n=88)$ & 0.4 \\
\hline Very confident & $55(65)$ & $46(62)$ & $62(71)$ & \\
\hline More confident than unsure & $16(19)$ & $17(23)$ & $20(23)$ & \\
\hline Neutral & $5(6)$ & $8(11)$ & $3(3)$ & \\
\hline More unsure than confident & $8(10)$ & $2(3)$ & $2(2)$ & \\
\hline Not at all confident & 0 & $1(1)$ & $1(1)$ & \\
\hline How many days of school did your child miss because of pain? & $(n=82)$ & $(n=73)$ & $(n=88)$ & 0.43 \\
\hline No days missed & $45(55)$ & $36(49)$ & $50(57)$ & \\
\hline Part of one day & $5(6)$ & $9(12)$ & $15(17)$ & \\
\hline One to two days & $25(30)$ & $19(26)$ & $16(18)$ & \\
\hline Three to four days & $4(5)$ & $5(7)$ & $3(3)$ & \\
\hline More than four days & $3(4)$ & $4(6)$ & $4(5)$ & \\
\hline $\begin{array}{l}\text { How many nights did your child have difficulty sleeping presumably due } \\
\text { to pain? }\end{array}$ & $(n=84)$ & $(n=74)$ & $(n=88)$ & 0.94 \\
\hline No sleepless nights & $38(45)$ & $34(46)$ & $37(42)$ & \\
\hline Part of one night & $15(18)$ & $11(15)$ & $18(20)$ & \\
\hline One to two nights & $16(19)$ & $22(30)$ & $23(26)$ & \\
\hline Three to four nights & $10(12)$ & $5(7)$ & $8(9)$ & \\
\hline More than four nights & $5(6)$ & $2(2)$ & $2(3)$ & \\
\hline How long did it take for your child to return to his/her normal diet? & $(n=84)$ & $(n=73)$ & $(n=88)$ & 0.07 \\
\hline No impact on diet & $61(73)$ & $40(55)$ & $53(60)$ & \\
\hline Part of one day & $12(14)$ & $18(25)$ & $11(13)$ & \\
\hline One to two days & $8(10)$ & $9(12)$ & $19(22)$ & \\
\hline Three to four days & $2(2)$ & $4(5)$ & $2(2)$ & \\
\hline More than four days & $1(1)$ & $2(3)$ & $3(3)$ & \\
\hline $\begin{array}{l}\text { How many work days did you miss because you were taking care of } \\
\text { your child? }\end{array}$ & $(n=70)$ & $(n=68)$ & $(n=78)$ & 0.95 \\
\hline No days missed & $41(59)$ & $38(56)$ & $44(57)$ & \\
\hline Part of one day & $9(13)$ & $11(16)$ & $11(14)$ & \\
\hline One to two days & $17(25)$ & $15(22)$ & $18(23)$ & \\
\hline Three to four days & $1(1)$ & $2(3)$ & $1(1)$ & \\
\hline More than four days & $1(1)$ & $2(3)$ & $4(5)$ & \\
\hline $\begin{array}{l}\text { I provide full-time care to my child and do not have other } \\
\text { employment. }\end{array}$ & $1(1)$ & 0 & 0 & \\
\hline
\end{tabular}

duration of access were recorded using custom website programming (Sublime Text). To minimize the risk of unaccounted co-interventions, participants in the $\mathrm{WBM}$ and video groups were asked to refrain from seeking out other educational materials.

\section{Statistical analysis and outcomes}

The per protocol analysis included participants who completed both the pre-intervention and postintervention knowledge questionnaires. The primary outcome was the pre-intervention to post-intervention difference (gain score) on the 21-item knowledge questionnaire in the ED and was analysed using the analysis of variance (ANOVA). Pairwise differences were explored using a Tukey adjustment for multiple comparisons. Secondary outcomes were analysed using the Kruskal-Wallis test and included caregiver confidence in recognizing pain and providing analgesia, the number of sleep-interrupted nights for both the caregiver and child, the number of days of work or school missed for the caregiver or child, respectively, and the number of days before resumption of a normal diet for the child. For each secondary outcome, we performed ordinal logistic regression models to examine the effect of the duration of the time that participants accessed the 
WBM and video post-discharge. To examine whether the participant's decision to access the intervention post-discharge influenced group differences in functional outcomes, we performed a sensitivity analysis in which Kruskal-Wallis tests were rerun for each functional outcome after removing participants in the WBM $(n=2)$ and video $(n=2)$ groups who did not access the respective interventions post-discharge. A between-group difference of $10 \%$ (two points) on the gain score was chosen as a minimal clinically important difference (MCID), based on a study of a video to educate caregivers about proper antibiotic use. ${ }^{25}$ Assuming a standard deviation (SD) of $20 \%$ from a previous study of an interactive Web-based intervention, ${ }^{26} 86$ participants per group were required to detect a $10 \%$ difference between all three groups at the $5 \%$ two-sided level of significance with $90 \%$ power. The sample size was increased by $10 \%$ per group to account for dropouts. Data were entered into a study-specific Excel spreadsheet and analysed using SPSS (version 24, IBM SPSS, Armonk, New York), and $p$ values of less than 0.05 were used to reject the null hypothesis of no difference between groups.

\section{RESULTS}

\section{Participants}

All 340 randomized participants completed each intervention. However, 29 did not complete the knowledge questionnaire. We analysed the results of the remaining 99 and 108 and 104 participants in the WBM, video, and SOC groups, respectively (Figure 1). The overall mean (SD) age of participants was 9.6 (4.2) years, of which 125/311 (40.2\%) were female (Table 2). Sixty-five participants did not complete the 120-hour survey.

\section{Primary outcome}

There was an increase in knowledge questionnaire scores from pre- to post-intervention (gain score) in all three groups. The greatest increase was seen in the video followed by the WBM and SOC groups (Table 3). There were significant overall betweengroup differences (delta) in mean gain score $(p<0.001)$. Participants in the video (delta $=2.3,95 \%$ confidence interval [CI]: $1.3,3.3 ; p<0.001)$ and WBM (delta $=1.6$; $95 \%$ CI: $0.5,2.6 ; p=0.002$ ) groups had significantly greater gain scores than the SOC group. The mean gain score in the video group was not significantly greater than that of the WBM group (delta $=0.7 ; 95 \%$ CI: -0.3 , $1.8 ; p=0.25$ ) (see Table 3 ). The duration of time that the interventions were accessed in the ED ranged from 8 to 15 minutes for the WBM and 5 minutes to load and view the video. In the WBM and video groups, 86 and 72 participants, respectively, accessed the interventions following discharge from the ED. In the covariate analysis, the mean gain score was not significantly different between WBM and video groups (delta $=-0.3$; 95\% CI: $-1.4,0.8 ; p=0.54)$.

\section{Secondary outcomes}

Greater than $60 \%$ of caregivers reported being very confident in their ability to manage their child's pain at home (Table 1). Roughly, half of caregivers reported that their child missed at least some school, and more than half reported difficulty sleeping presumably due to pain. Twenty-seven percent to $45 \%$ of caregivers reported some impact on their child's diet, and $41 \%$ to $44 \%$ reported missing work to take care of their child. There were no overall between-group differences in functional outcomes (see Table 1) even after removal of participants who did not access the WBM and video post-discharge (caregiver confidence, $p=0.41$; school absence, $p=0.39$; sleep, $p=0.85$; diet, $p=0.1$; work absence, $p=0.98$ ). There was no significant effect of duration that the WBM and video were accessed and overall group differences in caregiver confidence $(p=0.54)$, school absence $(p=0.2)$, sleep $(p=0.65)$, diet $(p=0.2)$, and work absence $(p=0.57)$.

\section{Participants lost to follow-up}

Demographic and outcome-specific details of participants who did not complete study procedures can be found in Table 4. Overall, there were no differences in demographic features between participants who did and did not complete the study.

\section{DISCUSSION}

This randomized, open-label trial of the effectiveness of digital media educational interventions among caregivers whose children sustained nonoperative fractures demonstrated that an interactive WBM and video provided superior knowledge acquisition to SOC verbal 


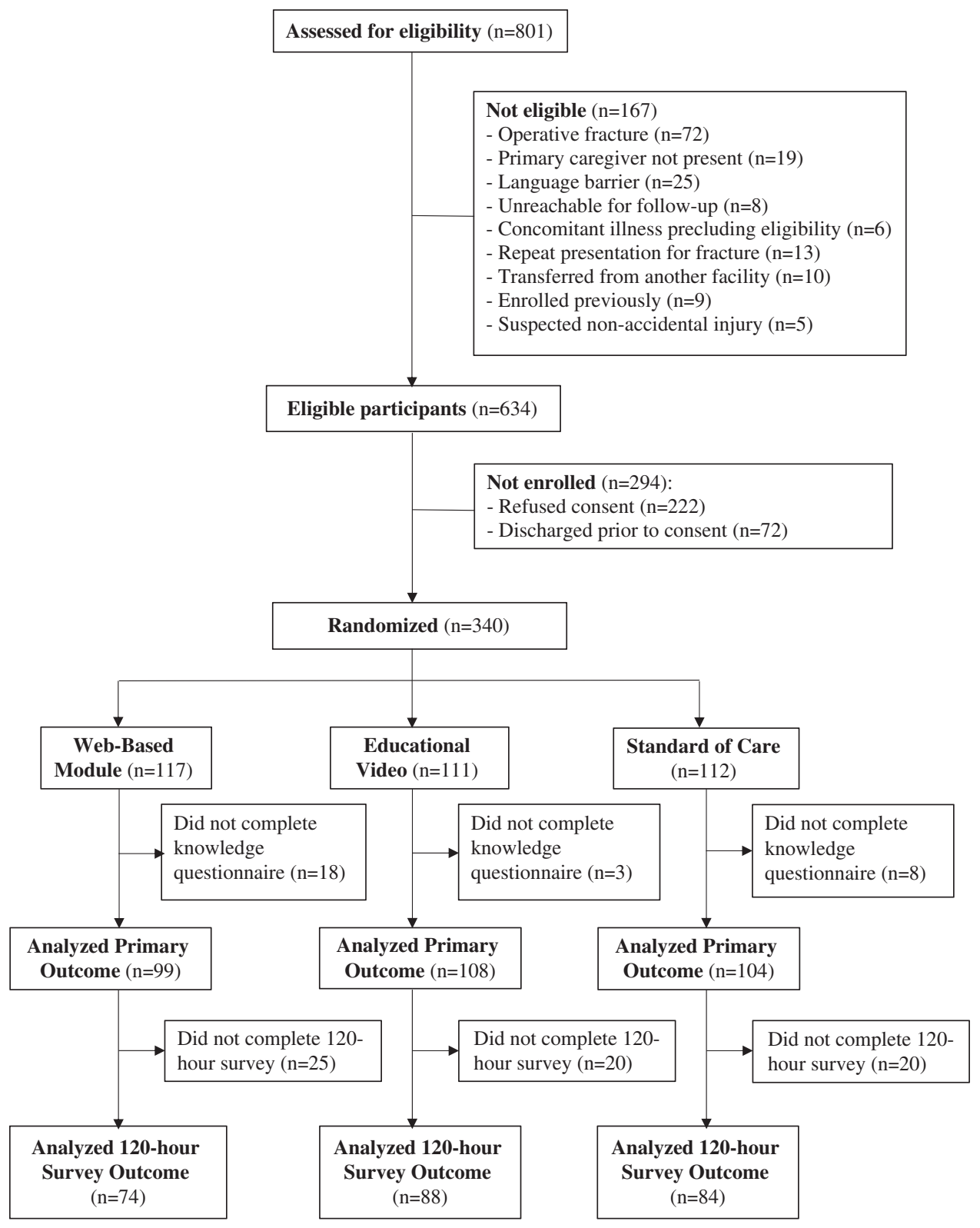

Figure 1. Flow of participants through the trial.

instructions. Furthermore, functional impairments across the entire sample were prevalent. Our findings suggest that digital media may provide an effective, standardized way to deliver discharge education in the busy ED environment.

Both the WBM and video were associated with a significantly greater gain score compared to the SOC by a margin that exceeded our MCID at the upper bound of the CI but not the lower bound. This suggests that, while our results were statistically significant, they may not be clinically significant if one considers the most conservative estimate of the between-group differences. However, our results parallel a growing body of literature in which multimedia technology has shown benefit when delivering discharge instructions in the ED. In previous work by our group, an interactive WBM and read-only website were associated with significantly greater knowledge acquisition than written and verbal information among caregivers of children with fever. ${ }^{26}$ Although it did not reach statistical significance, it was not surprising that the greatest gain score was associated with the video, because literacy has 


\begin{tabular}{|c|c|c|c|}
\hline & $\begin{array}{l}\text { Standard of } \\
\text { care } \\
(n=104)\end{array}$ & $\begin{array}{l}\text { Web-based } \\
\text { module } \\
(n=99)\end{array}$ & $\begin{array}{c}\text { Educational } \\
\text { video } \\
(n=108)\end{array}$ \\
\hline \multicolumn{4}{|l|}{ Sex of child $(\%)^{*}$} \\
\hline Female & $46(44.2)$ & $38(38.4)$ & $41(38)$ \\
\hline Male & $58(55.8)$ & $61(61.6)$ & $67(62)$ \\
\hline $\begin{array}{l}\text { Mean child age in years } \\
\text { (SD) }\end{array}$ & $9.3(4.2)$ & $9.4(4.2)$ & $10.1(4.2)$ \\
\hline \multicolumn{4}{|l|}{ Caregiver identity $(\%)^{*}$} \\
\hline Mother & $79(76)$ & $65(65.7)$ & $76(70.4)$ \\
\hline Father & $24(23.1)$ & $31(31.3)$ & $3(28.7)$ \\
\hline Other & $1(1)$ & $2(2)$ & $1(0.9)$ \\
\hline \multicolumn{4}{|l|}{ Previous fractures $(\%)^{*}$} \\
\hline Yes & $30(28.8)$ & $30(30.3)$ & $28(25.9)$ \\
\hline No & $74(71.2)$ & $69(69.7)$ & $80(74.1)$ \\
\hline \multicolumn{4}{|l|}{$\begin{array}{l}\text { Highest caregiver } \\
\text { education level }(\%)^{*}\end{array}$} \\
\hline University & 45 (43.3) & $44(44.4)$ & 36 (33.3) \\
\hline College & $47(45.2)$ & $38(38.4)$ & $45(41.7)$ \\
\hline Vocational & 0 & 0 & $3(2.8)$ \\
\hline High school & $9(8.7)$ & $13(13.1)$ & $21(19.4)$ \\
\hline Elementary school & $2(1.9)$ & $4(4)$ & 0 \\
\hline Declined to answer & $1(1)$ & 0 & $3(2.8)$ \\
\hline \multicolumn{4}{|l|}{$\begin{array}{l}\text { Previous or currently } \\
\text { employed in a health } \\
\text { care field }(\%)^{*}\end{array}$} \\
\hline Yes & 19 (18.3) & $16(16.2)$ & $12(11.1)$ \\
\hline No & $65(62.5)$ & $61(61.6)$ & 77 (71.3) \\
\hline Declined to answer & $20(19.2)$ & $22(22.2)$ & 19 (17.6) \\
\hline \multicolumn{4}{|l|}{ Fracture type $(\%)^{*}$} \\
\hline Upper extremity & $85(81.7)$ & $77(77.8)$ & 82 (75.9) \\
\hline Lower extremity & $19(18.3)$ & $22(22.2)$ & $25(23.1)$ \\
\hline Both & 0 & 0 & $1(0.9)$ \\
\hline \multicolumn{4}{|l|}{ Closed reduction $(\%)^{*}$} \\
\hline Yes & $21(20.2)$ & $23(23.2)$ & $27(25)$ \\
\hline No & $83(79.8)$ & $76(76.8)$ & $81(75)$ \\
\hline \multicolumn{4}{|l|}{ Management $(\%)^{*}$} \\
\hline Circular cast & 39 (37.5) & $40(40.4)$ & $44(40.8)$ \\
\hline Splint & $49(47.1)$ & $38(38.4)$ & 43 (39.8) \\
\hline Sling & $10(9.6)$ & $15(15.2)$ & 12 (11.1) \\
\hline No immobilization & $6(5.8)$ & $6(6)$ & 9 (8.3) \\
\hline
\end{tabular}

often been cited as a barrier to the comprehension of discharge instructions. ${ }^{27}$ Atzema et al. found that online videos led to significantly greater understanding of diagnoses and care among adult ED patients for a wide range of diagnoses, including fractures. ${ }^{28}$ Video discharge instructions in the ED have been associated with significantly greater knowledge acquisition in caregivers of children with gastroenteritis, ${ }^{29}$ bronchiolitis, ${ }^{29}$ fever, ${ }^{29,30}$ head injury, ${ }^{30}$ and antibiotic use. ${ }^{25}$ In terms of knowledge retention, Bloch et al. found that video discharge instructions provided to caregivers of children with wheezing, fever, vomiting, or diarrhea improved knowledge up to 5 days post-discharge. ${ }^{31}$

In our study, participants across all three groups had a correct response rate of just over $60 \%$ on the pre-intervention knowledge questionnaire. This underscores the need for caregiver education on pain management and is consistent with ample evidence that caregivers $^{32}$ and patients ${ }^{10,11,33,34}$ often lack a complete understanding of discharge instructions. Despite a relative lack of baseline knowledge, gain scores across groups were modest. Even the most effective intervention, the online video, exhibited only a $12 \%$ increase in knowledge score. This suggests either a need for more effective educational strategies or, more likely, ensuring that families receive discharge education, an environment that is more conducive to knowledge retention than a busy ED. To ensure that study participants did not leave the ED prior to their completion of the second knowledge questionnaire, the interventions were administered during the ED visit rather than at discharge. However, the noise level, distractions, and associated stressors in the acute care setting may have been a barrier to optimal information processing and knowledge retention. ${ }^{24}$ Although the home environment, together with repeated viewing of the Web-based interventions, may have led to greater knowledge acquisition, we did not measure knowledge acquisition post-discharge. Instead, we focused on functional outcomes because we believed them to be more salient to the clinical application of our findings.

The success of educational interventions is ultimately predicated upon an improvement in functional outcomes. Our study was not powered to detect betweengroup differences in functional outcomes. Although the absence of benefit may have been due to lack of statistical power, another possibility is that our 5-day survey may not have been sufficiently sensitive to change. Nevertheless, a large proportion of children experienced deficits in school attendance, sleep, and diet, consistent with the findings of Drendel et al. in their two studies of post-discharge fracture pain in children. ${ }^{20,35}$

The practicality of digital media educational interventions for caregiver education lies in their accessibility, consistency of information, and the ability to easily incorporate new information. Digital media can 
Digital media educational interventions for fracture pain

Table 3. Mean (SD) knowledge and gain scores (maximum score of 21)

\begin{tabular}{|c|c|c|c|c|c|}
\hline & $\begin{array}{c}\text { Mean (SD) } \\
\text { pre-test score }\end{array}$ & $\begin{array}{c}\text { Mean (SD) } \\
\text { post-test score }\end{array}$ & $\begin{array}{l}\text { Mean (SD) } \\
\text { gain score* }\end{array}$ & $\begin{array}{c}\text { Mean (SD) } \\
\text { number of logins }\end{array}$ & $\begin{array}{l}\text { Mean (SD) access } \\
\text { duration (seconds) }\end{array}$ \\
\hline Standard of care $(n=104)$ & $13.3(3.2)$ & $13.7(3.4)$ & $0.4(2.3)$ & $\mathrm{N} / \mathrm{A}$ & $\mathrm{N} / \mathrm{A}$ \\
\hline Web-based module $(n=99)$ & $12.3(3.7)$ & $14.3(4)$ & $2(3.1)$ & $1.3(0.6)$ & $930.7(802.7)$ \\
\hline Educational video $(n=108)$ & $12.6(3.8)$ & $15.3(3.3)$ & $2.7(4)$ & $1.2(0.6)$ & $704.6(796.3)$ \\
\hline$p$-value & 0.12 & 0.005 & $<0.001$ & & \\
\hline
\end{tabular}

\begin{tabular}{|c|c|c|c|}
\hline & $\begin{array}{l}\text { Standard } \\
\text { of care }\end{array}$ & $\begin{array}{l}\text { Web-based } \\
\text { module }\end{array}$ & $\begin{array}{c}\text { Educational } \\
\text { video }\end{array}$ \\
\hline \multicolumn{4}{|c|}{ Did not complete knowledge questionnaire or 5-day survey } \\
\hline Sex of child $(\%)^{*}$ & $(n=8)$ & $(n=18)$ & $(n=3)$ \\
\hline Female & $2(25)$ & $8(44)$ & $2(67)$ \\
\hline Male & $6(75)$ & $10(56)$ & $1(33)$ \\
\hline $\begin{array}{l}\text { Mean child age in years } \\
\text { (SD) }\end{array}$ & $9.3(4.1)$ & $9.3(4.3)$ & $9.5(2.1)$ \\
\hline Mean (SD) pre-test score & $8(6.3)$ & $7.9(6)$ & $4.5(6.4)$ \\
\hline \multicolumn{4}{|c|}{ Did not complete 5-day survey } \\
\hline Sex of child $(\%)^{*}$ & $(n=20)$ & $(n=25)$ & $(n=20)$ \\
\hline Female & $9(45)$ & $9(36)$ & $10(50)$ \\
\hline Male & $11(54)$ & $16(64)$ & $10(50)$ \\
\hline Mean age in years (SD) & $9.5(4.2)$ & $9.5(4)$ & $10.1(3.8)$ \\
\hline Mean (SD) pre-test score & $12.9(3.5)$ & $10.7(3.6)$ & $11.3(4.3)$ \\
\hline Mean (SD) post-test score & $13.8(3.4)$ & $11.7(4.7)$ & $14.5(3.9)$ \\
\hline Mean (SD) gain score ${ }^{\dagger}$ & $0.9(2.8)$ & $1(3.1)$ & $3.2(4.2)$ \\
\hline Mean (SD) number of logins & N/A & $1.2(0.5)$ & $1(0)$ \\
\hline Mean (SD) access & $\mathrm{N} / \mathrm{A}$ & 842.1 & 629.8 \\
\hline duration (seconds) & & (424.4) & (491.6) \\
\hline \multicolumn{4}{|c|}{$\begin{array}{l}\text { N/A = not applicable; } \mathrm{SD}=\text { standard deviation. } \\
\text { *Percentage of total in column. } \\
\text { 'Difference between pre-test and post-test score. Value was obtained by subtracting the } \\
\text { pre-test from the post-test score for each participant then calculating the mean. }\end{array}$} \\
\hline
\end{tabular}

also be self-administered, making them less resource intensive than verbal discharge instructions. Caregivers and children are reportedly motivated to use Web-based resources, trust the information provided, and use interactive features to manage pain at home. ${ }^{16}$ Additionally, websites from a physician or medical association appear to be most often accessed, suggesting that caregivers have a preference for information from health care professionals. ${ }^{19}$ Our study has established that digital media educational interventions improve caregiver knowledge. However, to definitively establish their clinical utility and support their cost-effectiveness, future studies should be powered to detect clinically important improvements in a wide range of functional outcomes.

\section{LIMITATIONS}

Our sample included caregivers who were highly educated, proficient English speakers. Therefore, our findings may have limited generalizability to a non-English speaking population. We chose not to standardize the SOC intervention, and the knowledge questionnaire likely contained items that were not addressed by the SOC. Although this may have inflated the effect size, we feel that this approach was a more accurate comparison between the Web-based interventions and the discharge teaching that a family actually receives in contrast to what they would ideally receive if the SOC were standardized. Furthermore, unlike the WBM and video groups, participants in the SOC were not asked to avoid seeking out other educational materials. A validated scale was not used to measure functional outcomes leading to the possibility of measurement bias. Although such scales exist, items were either not applicable ${ }^{36,37}$ or the scale was developed in a post-surgical population. ${ }^{38}$

\section{CONCLUSIONS}

We have demonstrated that a WBM and video are associated with greater caregiver knowledge acquisition over SOC verbal instructions with respect to managing children's pain following a fracture. Although the differences may not be clinically significant, these interventions may provide standardized and efficient caregiver education, and our findings are an important initial step in their further development. However, a large proportion of children experienced deficits in school, sleep, and diet, and there was no evidence of benefit to the digital media interventions. Further study 
is needed to determine the best approaches to reducing functional limitations due to pain following nonoperative fractures in children.

Acknowledgements: We would like to acknowledge Keri Hainsworth, PhD; Steven J. Weisman, MD; Dana Mueller, MD; Shaun Summerill, MD; Jill Keyes, MD, MS RN; Jeff Surges; and Brian Herteen for their role in the development and production of the video intervention. Prior presentations include Canadian Paediatric Society, June 2017, Vancouver, BC. This study was funded through a resident research grant by the Department of Paediatrics, Western University.

Competing interests: None declared.

\section{SUPPLEMENTARY MATERIAL}

To view supplementary material for this article, please visit https://doi.org/10.1017/cem.2017.414

\section{REFERENCES}

1. Spady DW, Saunders DL, Schopflocher DP, et al. Patterns of injury in children: a population-based approach. Pediatrics 2004;113(3):522-9.

2. Chamberlain JM, Patel KM, Pollack MM, et al. Recalibration of the pediatric risk of admission score using a multiinstitutional sample. Ann Emerg Med 2004;43(4):461-8.

3. Landin LA. Epidemiology of children's fractures. 7 Pediatr Orthop B 1997;6(2):79-83.

4. Drendel AL, Lyon R, Bergholte J, et al. Outpatient pediatric pain management practices for fractures. Pediatr Emerg Care 2006;22(2):94-9.

5. Herndon JB, Chaney M, Carden D. Health literacy and emergency department outcomes: a systematic review. Ann Emerg Med 2011;57:334-45.

6. Maimon MS, Marques L, Goldman RD. Parental administration of analgesic medication in children after a limb injury. Pediatr Emerg Care 2007;23(4):223-6.

7. Gill M, Drendel AL, Weisman SJ. Parent satisfaction with acute pediatric pain treatment at home. Clin 7 Pain 2013;29(1):64-9.

8. De Maio VJ, Joseph DO, Tibbo-Valeriote H, Cabanas JG, et al. Variability in discharge instructions and activity restrictions for patients in a children's ED postconcussion. Pediatr Emerg Care 2014;30(1):20-5.

9. Sarsfield MJ, Morley EJ, Callahan JM, Grant WD, et al. Evaluation of emergency medicine discharge instructions in pediatric head injury. Pediatr Emerg Care 2013;29(8):884-7.

10. Engel KG, Heisler M, Smith DM, Robinson CH, et al. Patient comprehension of emergency department care and instructions: are patients aware of when they do not understand? Ann Emerg Med 2009;53(4):454-61.

11. Engel KG, Buckley BA, Forth VE, McCarthy DM, et al. Patient understanding of emergency department discharge instructions: where are knowledge deficits greatest? Acad Emerg Med 2012;19(9):E1035-44.

12. Kobak KA, Stone W, Wallace E, Warren Z, et al. A web-based tutorial for parents of young children with autism: results from a pilot study. Telemed 7 E-Health 2011;17(10):804-8.

13. Boren SA, Gunlock TL, Peeples MM, Krishna S. Computerized learning technologies for diabetes: a systematic review. 7 Diabet Sci Tech 2008;2(1):139-46.

14. Walker ER, Wexler B, Dilorio C, Escoffery C, et al. Content and characteristics of goals created during a self-management intervention for people with epilepsy. 7 Neurosci Nurs 2009;41(6):312-21.

15. Bussey-Smith KL, Rossen RD. A systematic review of randomized controlled trials evaluating the effectiveness of interactive computerized asthma patient education programs. Ann Allergy Astbma Immunol 2007;98(6):507-16.

16. Stinson J, McGrath P, Hodnett E, et al. Usability testing of an online self-management program for adolescents with juvenile idiopathic arthritis. $\mathcal{f}$ Med Int Res 2010;12(3):e30.

17. File T, Ryan C. Computer and Internet use in the United States: 2013. Washington, DC: 2015 Available at: https:// www.census.gov/history/pdf/acs-internet2013.pdf.

18. Park G, Weiss SJ, Repar P. Randomized single-blinded clinical trial on effects of nursery songs for infants and young children's anxiety before and during head computed tomography. Am 7 Emerg Med 2016;34(3):663.

19. Bianco A, Zucco R, Nobile CG, Pileggi C, et al. Parents seeking health-related information on the Internet: crosssectional study. 7 Med Internet Res 2013;15(9):e204.

20. Drendel AL, Gorelick MH, Weisman SJ, et al. A randomized clinical trial of ibuprofen versus acetaminophen with codeine for acute pediatric arm fracture pain. Ann Emerg Med 2009;54(4):553-60.

21. Stockvault B G. 2004-2015. Available at: http://www.stock vault.net/.

22. Stockfreeimages; 2012-2015. Available at: http://www.stock freeimages.com/.

23. Mueller D, Summerill S, Keyes J, Drendel AL. (eds). Parental knowledge and perceptions of the outpatient treatment of acute pain. Annual Meeting of the Pediatric Academic Society. Baltimore, MD: E-PAS; 2009.

24. Saidinejad M, Zorc J. Mobile and web-based education: delivering emergency department discharge and aftercare instructions. Pediatr Emerg Care 2014;30(3):211-6.

25. Schnellinger M, Finkelstein M, Thygeson MV, Vander Velden H, et al. Animated video vs pamphlet: comparing the success of educating parents about proper antibiotic use. Pediatrics 2010;125(5):990-6.

26. Hart L, Nedadur R, Reardon J, Sirizzotti N, et al. Webbased tools for educating caregivers about childhood fever: a randomized controlled trial. Pediatr Emerg Care 2016; epub, doi:10.1097/PEC.0000000000000936.

27. Lukoschek P, Fazarri M, Marantz P. Patient and physician factors predict patients' comprehension of health information. Patient Educ Couns 2003;50(2):201-10.

28. Atzema CL, Austin PC, Wu L, Brzozowski M, et al. Speak fast, use jargon, and don't repeat yourself: a randomized trial assessing the effectiveness of online videos to supplement emergency department discharge instructions. PLoS One 2013;8(11):e77057.

29. Wood EB, Harrison G, Trickey A, Friesen MA, et al. Evidence-based practice: video-discharge instructions in the 
pediatric emergency department. 7 Emerg Nurs 2017; 43(4):316-21.

30. Ismail S, McIntosh M, Kalynych C, Joseph M, et al. Impact of video discharge instructions for pediatric fever and closed head injury from the emergency department. 7 Emerg Med 2016;50(3):e177-83.

31. Bloch SA, Bloch AJ. Using video discharge instructions as an adjunct to standard written instructions improved caregivers' understanding of their child's emergency department visit, plan, and follow-up: a randomized controlled trial. Pediatr Emerg Care 2013;29(6):699-704.

32. Abou-Karam M, Dube S, Kvann HS, et al. Parental report of morphine use at home after pediatric surgery. 7 Pediatr 2015;167(3):599-604.

33. Makaryus AN, Friedman EA.. Patients' understanding of their treatment plans and diagnosis at discharge. Mayo Clin Proc 2005;80(8):991-4.
34. Hwang V, Trickey AW, Lormel C, Bradford AN, et al. Are pediatric concussion patients compliant with discharge instructions? 7 Trauma Acute Care Surg 2014;77(1): $117-22$.

35. Drendel AL, Brousseau DC, Gorelick MH. Pain assessment for pediatric patients in the emergency department. Pediatrics 2006;117(5):1511-8.

36. Plint AC, Gaboury I, Owen J, et al. Activities scale for kids: an analysis of normals. $\mathcal{F}$ Pediatr Orthop 2003;23(6):788-90.

37. Msall ME, Diguardio K, Duffy LC, LaForest S, et al. WeeFIM. Normative sample of an instrument for tracking functional independence in children. Clin Pediatr (Phila) 1994;33(7):431-8.

38. Ewing-Cobbs L, Bloom DR, Prasad MR, Waugh JK, et al. Assessing recovery and disability after physical trauma: the Pediatric Injury Functional Outcome Scale. 7 Pediatr Psychol 2014;39(6):653-65. 